EDITORIAL

\title{
Gut microbiota modulation: A tailored approach for the prevention of chronic diseases
}

\author{
CONCETTINA FENGA \\ Department of Biomedical and Dental Sciences and Morphofunctional Imaging, Occupational \\ Medicine Section, University of Messina, I-98125 Messina, Italy
}

Received January 14, 2022; Accepted January 21, 2022

DOI: $10.3892 /$ br.2022.1506

During its entire existence, since conception, humanity is constantly exposed to a heterogeneity of external factors, including air and water pollutants, metals, radiations, disrupting chemicals and organic compounds, biological agents. Additionally, the individual occupational milieu, the specific diet and lifestyle habits all represent a source of differential exposures. In conjunction, such factors constitute to the so-called external exposome, which dynamically shapes human health. The external exposome affects the genetics, epigenetics and immune system of humans, thus influencing the occurrence of chronic pathologies, such as cardiometabolic, cerebrovascular, neurological and pulmonary diseases, as well as cancer $(1,2)$.

The current scientific findings are constantly strengthening the concept that the internal exposome, known as the entire population of microorganisms inhabiting the whole exposed surfaces of the human body, constitute the active interface, which modulates (and in turn is shaped by) the whole external triggers. In particular, the intestinal microbiota represents a community of microbes (bacteria, but also viruses, archaea, eukaryotes) able to change the final bioavailability and overall toxicity of xenobiotics, hence profoundly affecting the general health status of the human body $(3,4)$.

There is a mutual interplay occurring between the gut microbiota and the external exposome. Recently, it has been evidenced that the specific composition and functionality of the intestinal microbial community are strongly conditioned by the nature and timing of the environmental and occupational

Correspondence to: Professor Concettina Fenga, Department of Biomedical and Dental Sciences and Morphofunctional Imaging, Occupational Medicine Section, University of Messina, 1 Consolare Valeria Street, I-98125 Messina, Italy

E-mail: cfenga@unime.it

Key words: microbiota, exposome, environmental and occupational exposure, chronic diseases, nutrition, nutraceuticals, probiotics, biomarkers, integrated medicine exposures. On the other hand, the intestinal microbial health influences the individual response to external exposures: The maintenance of a status of microbial health (so-called eubiosis) may be protective against the toxic effects of environmental detrimental factors, contrariwise, the intestinal dysbiosis may be a trigger for the development or the worsening of chronic diseases (5).

In particular, nowadays, in the industrialized era, the workplace may represent a primary source of chemical, physical and biological hazards influencing the associations occurring between our external and internal exposome, and their role in human health (6).

From an occupational perspective, the latest review from the International Labour Organization (ILO), indicates that, in order to reduce the socio-economic burden of occupational-related exposures, the epidemiological studies may be flanked by robust research on cancer and other non-communicable diseases (lung diseases, neurological pathologies and reproductive issues), as well as research on infectious diseases which may be aggravated by the exposure to toxicants (7). The current COVID-19 outbreak represents a lesson to learn in order to improve this particular aspect (8). On these bases, risk assessment should appraise the interaction of the intestinal commensals (and pathogens) and toxicants.

Moreover, its active modulation through different approaches (from holistic nutritional programs to the administration of specific nutraceuticals or probiotics) may be a non-invasive and effective tool to positively affect the intestinal microbial composition and, hence, to prevent and defeat the dysbiosis (9).

Given that prevention represents a mainstay between the scopes of occupational medicine, this integrated approach may be explored as a potential personalized intervention to reduce the risk of occurrence or worsening of chronic diseases. Overall, microbiota-related research may aid health risk assessors to re-evaluate the mechanisms through which toxicants and pathogens interact with exposed individuals.

Future research may tackle the yet underexplored molecular mechanisms through which toxicants affect gut microbial composition and vice versa. Additionally, novel studies are required to uncover biomarker of exposure and effect within the gut microbiome. 
On these premises, the present Special Issue aims to comprise a collection of scientific contributions to fill the research gap uncovering the mutual association between intestinal microbiota modulation and chronic diseases towards a more translational and personalized medicine.

\section{Acknowledgements}

Not applicable.

\section{Funding}

No funding was received.

\section{Availability of data and materials}

Not applicable.

\section{Author's contributions}

CF contributed to the writing, drafting, revising, editing, reviewing, and the conception and design of this Editorial. The author has read and approved the final version.

\section{Ethics approval and consent to participate}

Not applicable.

\section{Patient consent for publication}

Not applicable.

\section{Competing interests}

The author declares that she has no competing interests.

\section{References}

1. Vermeulen R, Schymanski EL, Barabási AL and Miller GW: The exposome and health: Where chemistry meets biology. Science 367: 392-396, 2020.

2. Vivarelli S, Salemi R, Candido S, Falzone L, Santagati M, Stefani S, Torino F, Banna GL, Tonini G and Libra M: Gut microbiota and cancer: from pathogenesis to therapy. Cancers (Basel) 11: 38, 2019.

3. Giambò F, Italia S, Teodoro M, Briguglio G, Furnari N, Catanoso R, Costa $C$ and Fenga C: Influence of toxic metal exposure on the gut microbiota (Review). World Acad Sci J 3: $19,2021$.

4. Giambò F, Teodoro M, Costa $\mathrm{C}$ and Fenga C: Toxicology and microbiota: How do pesticides influence gut microbiota? A review. Int J Environ Res Public Health 18: 5510, 2021.

5. Nazaroff WW: Embracing microbes in exposure science. J Expo Sci Environ Epidemiol 29: 1-10, 2019.

6. Bocato MZ, Bianchi Ximenez JP, Hoffmann C and Barbosa F: An overview of the current progress, challenges, and prospects of human biomonitoring and exposome studies. J Toxicol Environ Health B Crit Rev 22: 131-156, 2019.

7. International Labour Organization (ILO): World Day for Safety and Health at Work 2021. ILO, Geneva, 2021. https://www.ilo.org/ global/topics/safety-and-health-at-work/events-training/eventsmeetings/safeday2021/lang--en/index.htm. Accessed April 28, 2021.

8. Cammarota G, Giambò F and Ianiro G: Clostridioides difficile infection during the COVID-19 pandemic: A gut microbiota-based relationship. Pol Arch Intern Med 131: 116-117, 2021.

9. Vijay A and Valdes AM: Role of the gut microbiome in chronic diseases: A narrative review. Eur J Clin Nutr: Sep 28, 2021 (Epub ahead of print). 